\title{
In-Vivo Measurement of Bone Electric Properties
}

\author{
Wyss Balmer Thomas ${ }^{1}$, Ansó Juan², Stahel Andreas ${ }^{3}$, Büchler Philippe ${ }^{1}$ \\ ${ }^{1}$ Institute of Surgical Technologies and Biomechanics/University of Bern \\ Stauffacherstrasse 78, Bern, Switzerland \\ ${ }^{2}$ ARTORG Center for Biomedical Engineering Research, University of Bern \\ ${ }^{3}$ Mathematics, Bern University of Applied Sciencesm, University of Bern \\ Thomas.wyss@istb.unibe.ch; juan.anso@artorg.unibe.ch
}

\section{Extended Abstract}

Cochlear implant is a successful aid for hearing impaired people. A new surgical procedure to access the cochlea aims at replacing the invasive mastoidectomy by minimal invasive drilling using a surgical robot. However, safety is a key aspect for the clinical acceptance of robotic assistance, since the drilling trajectory passes at very low distances from critical structures like the facial nerve. Damage to the facial nerve could have severe consequences for the patient and can lead to facial paralysis.

Since the early eighties several researchers have proposed facial nerve monitoring as a safe and effective intraoperative technique to avoid iatrogenic damage of the facial nerve during tissue removal in the mastoid [1]-[7] . In neuromonitoring, a pulsed electric current is imposed between a cathode placed on surgical tool and a reference anode on the patient's chest. This technique could be used intra-operatively to monitor drill to facial nerve distance, while removing mastoid tissue in the proximity of the facial nerve. For a given stimulus current, if drill to facial nerve distance decreases below a certain level, an action potential response is created and propagated through the nerve, and contraction of subjacent facial muscles can be measured as an electromyogram (EMG) response. It has been shown that a relationship exists between measured EMG response and drill bit to facial nerve distance, but it is difficult to give an accurate distance prediction only based on stimulation current[8], [9]. The large variability in the drill to facial nerve distance relationship, most likely due to bone density differences among patients, does not still allow precise (submillimetre accurate) functional guidance during robotic surgery into the mastoid. The goal of this study is to evaluate bone electric properties of in-vivo mastoid bone to get a deeper knowledge of the propagation of electric currents.

Bone impedance was determined in-vivo by impedance spectroscopy. Two electrode probes were inserted into tunnels drilled in the mastoid bone of three sheep (animal model). For each animal, several parallel trajectories were drilled. Impedance measurements were performed after insertion of the electrodes in different pairs of trajectories. Several currents - from $100 \mu \mathrm{A}$ to $500 \mu \mathrm{A}$ - as well as frequencies - $10 \mathrm{~Hz}$ to $1 \mathrm{kHz}$ - were used for the measurements. The measured impedances were correlated to the bone density (from computer tomography scans) and to inter-electrode distances. Finally, a simple equivalent electronic circuit was used to determine intrinsic bone electric properties.

Results showed that the impedance measured in-vivo could be described by a simple electronic circuit composed of a resistor in series with a constant phase element. Interestingly, the same set of parameters could be used to describe the behaviour of the constant phase element for all the experimental measurements (likely due to polarization of the electrode (stainless steel-tissue interface). Finally, the resistor component of the circuit showed a high correlation with bone density and inter-electrode distance (volume conductor model), which corresponds to the representation of bone tissue as a perfect resistor.

In conclusion, a simple electric model can be used to calculate the complex impedance of the mastoid bone based on pre-operative images and calibrated inter-electrode distances. 3 dimensional bone density information could be used to enhance the accuracy of facial nerve monitoring during robotic surgical procedures in the mastoid.

\section{Reference}

[1] T. E. Delgado, W. A. Bucheit, H. R. Rosenholtz, and S. Chrissian, "Intraoperative monitoring of facial muscle evoked responses obtained by intracranial stimulation of the facial nerve: a more accurate technique for facial nerve dissection.," Neurosurgery, vol. 4, no. 5, pp. 418-21, 1979.

[2] H. Silverstein, E. Smouha, and R. Jones, "Routine identification of the facial nerve using electrical stimulation during otological and neurotological surgery," Laryngoscope, vol. 98, no. 7, pp. 726-30, 1988.

[3] J. P. Leonetti, G. J. Matz, P. G. Smith, and D. L. Beck, "Facial nerve monitoring in otologic surgery: clinical indications and intraoperative technique," Ann. Otol. Rhinol. Laryngol., vol. 99, no. 11, pp. 911-8, 1990. 
[4] R. K. Jackler and S. H. Selesnick, "Indications for cranial nerve monitoring during otologic and neurotologic surgery," Am. J. Otol., vol. 15, no. 5, pp. 611-3, 1994.

[5] L. Wilson, E. Lin, and A. Lalwani, "Cost-effectiveness of intraoperative facial nerve monitoring in middle ear or mastoid surgery," Laryngoscope, vol. 113, no. 10, pp. 1736-45, 2003.

[6] D. Bernardeschi, N. Meskine, N. Al Otaibi, R. Ablonczy, M. Kalamarides, A. B. Grayeli, and O. Sterkers, "Continuous facial nerve stimulating burr for otologic surgeries," Otol. Neurotol., vol. 32, no. 8, pp. 1347-51, 2011.

[7] S. E. Heman-Ackah, S. Gupta, and A. K. Lalwani, "Is facial nerve integrity monitoring of value in chronic ear surgery?" Laryngoscope, vol. 123, no. 1, pp. 2-3, 2013.

[8] J. Ansó, C. Stahl, N. Gerber, T. Williamson, K. Gavaghan, K. M. Rösler, M.-D. Caversaccio, S. Weber, and B. Bell, "Feasibility of Using EMG for Early Detection of the Facial Nerve During Robotic Direct Cochlear Access," Otol. Neurotol., vol. 35, no. 3, pp. 545-54, 2014.

[9] J. Ansó, C. Dür, K. Gavaghan, H. Rohrbach, N. Gerber, T. Williamson, E. M. Calvo, T. W. Balmer, C. Precht, D. Ferrario, M. S. Dettmer, K. M. Rösler, M. D. Caversaccio, B. Bell, and S. Weber, "A Neuromonitoring Approach to Facial Nerve Preservation During Image-guided Robotic Cochlear Implantation," Otol. Neurotol., vol. 37, no. 1, pp. 89-98, 2016. 